\section{Occurrence of polymyalgia rheumatica in rheumatoid arthritis}

Polymyalgia rheumatica and rheumatoid arthritis may be difficult to differentiate in elderly patients. Polymyalgic symptoms are common in the prodromal phase of rheumatoid arthritis and, as specific diagnostic tests do not exist for either condition, criteria for diagnosis of the diseases are based largely on clinical features. ${ }^{12}$ The presence of synovitis similar to rheumatoid arthritis in some patients with polymyalgia rheumatica causes further problems. ${ }^{3}$ It is generally thought, however, that polymyalgia rheumatica does not occur in patients with rheumatoid arthritis; indeed, a diagnosis of rheumatoid arthritis has been used as a criterion for excluding polymyalgia rheumatica. ${ }^{34}$ We report the occurrence of polymyalgia rheumatica in patients who already had rheumatoid arthritis.

\section{Case reports}

Five patients with previously established classical rheumatoid arthritis developed typical polymyalgia rheumatica; they rapidly became incapacitated by the symptoms of polymyalgia when their rheumatoid arthritis was well controlled or quiescent. Their shoulders had not been affected previously. The onset of polymyalgia was sudden (less than two weeks in three patients), and rheumatoid arthritis in the joints previously affected did not worsen. No patient showed evidence of a recent bacterial or viral infection or responded when their nonsteroidal anti-inflammatory drugs were changed, but all patients responded to prednisolone. The table summarises the clinical features of the five patients and indicates the presence of the criteria for diagnosis of polymyalgia rheumatica as evaluated by Bird et al ${ }^{1}$; the presence of three out of seven criteria strongly suggests polymyalgia rheumatica. None of our patients was able to turn over in bed, and all had a considerably higher erythrocyte sedimentation rate than had previously been recorded. The polymyalgia rheumatica was followed up for a minimum of 18 months; no patient showed evidence of progression of the rheumatoid arthritis. A more detailed account of one case is given below. Case 1 -In 1980 a 71 year old man developed rheumatoid arthritis that mainly affected his hands and feet and was well controlled with non-steroidal antiinflammatory drugs. His erythrocyte sedimentation rate was $20 \mathrm{~mm}$ in the first hour. In June 1983, in less than a week, he developed aching, stiffness, and weakness of his shoulders and pelvic girdle muscles and could no longer roll over in bed. The severity of his symptoms was disproportionate to the mild rheumatoid synovitis of his wrists, elbows, and knees. His erythrocyte sedimentation rate was now $100 \mathrm{~mm}$ in the first hour; a temporal artery biopsy specimen was normal. He was treated with prednisolone $30 \mathrm{mg}$ daily and within 24 hours had greatly improved. In August 1985 he was well and free of symptoms taking prednisolone $5 \mathrm{mg}$ every other day.

Clinical features of patients with rheumatoid arthritis $(R A)$ and polymyalgia rheumatica $(P R)$

\begin{tabular}{|c|c|c|c|c|c|}
\hline & \multicolumn{5}{|c|}{ Case No } \\
\hline & 1 & 2 & 3 & 4 & 5 \\
\hline Age (years) & 71 & 80 & 63 & 78 & 71 \\
\hline Sex & $M$ & $\mathrm{~F}$ & $\mathrm{~F}$ & M & $\mathrm{F}$ \\
\hline Period between onset of RA and of PR (years) & 3 & 28 & 22 & 5 & 5 \\
\hline \multicolumn{6}{|l|}{ Rheumatoid arthritis: } \\
\hline Seropositive & + & + & + & + & + \\
\hline Erosive & + & + & + & + & + \\
\hline Active at onset of PR & + & - & - & - & + \\
\hline \multicolumn{6}{|l|}{ Erythrocyte sedimentation rate $(\mathrm{mm}$ in $\mathrm{lst} \mathrm{h})$ : } \\
\hline Before onset of PR & 20 & - & 33 & 22 & - \\
\hline At onset of PR & 100 & 74 & 75 & 57 & 120 \\
\hline Duration of follow up of PR (months) & 31 & 18 & 31 & 28 & 27 \\
\hline \multicolumn{6}{|l|}{ Presence of diagnostic criteria ${ }^{1}$ for $\mathrm{PR}$ : } \\
\hline Pain or stiffness in shoulder & + & + & + & + & + \\
\hline Onset $<2$ weeks' duration & + & + & - & + & - \\
\hline Erythrocyte sedimentation rate $>40 \mathrm{~mm}$ in $1 \mathrm{st} h$ & + & + & + & + & + \\
\hline Morning stiffness $>1$ hour & + & + & + & + & + \\
\hline Age $>65$ & + & + & - & + & + \\
\hline Depression or weight loss & - & - & - & - & + \\
\hline Bilateral tenderness of upper arm & + & + & + & + & + \\
\hline
\end{tabular}

\section{Comment}

This is the first report of polymyalgia rheumatica occurring as a distinct entity in patients with rheumatoid arthritis. Confident diagnoses were possible because of the abrupt onset of symptoms of polymyalgia rheumatica in patients whose rheumatoid arthritis was quiescent or only moderately active when they were receiving non-steroidal anti-inflammatory drugs alone. A diagnosis of polymyalgia rheumatica would have been more difficult if their shoulders had previously been affected or if their rheumatoid arthritis had not been relatively quiescent. Temporal (giant cell) arteritis occurs in patients with rheumatoid arthritis, ${ }^{5}$ and its distinctive features probably facilitate its identification in such cases. In contrast, the similarity between the clinical features of polymyalgia rheumatica and rheumatoid arthritis probably means that many cases of polymyalgia rheumatica pass unrecognised.

At the onset of the new symptoms some of our patients were treated with non-steroidal anti-inflammatory drugs because the polymyalgia rheumatica was initially thought to be a flare of rheumatoid activity. In such cases it is important to make an accurate diagnosis of polymyalgia rheumatica because in this condition there is no controversy over the use of steroids.

1 Bird HA, Esselinckx W, Dixon AStJ, et al. An evaluation of criteria for polymyalgia rheumatica. Ann Rheum Dis 1979;38:434-9.

2 Ropes MW. Diagnostic criteria for rheumatoid arthritis, 1958 revision. Ann Rheum Dis 1959;18: 49-51

3 Healey LA. Long-term follow-up of polymyalgia rheumatica: evidence for synovitis. Semin Arthritis Rheum 1984;13:322-8.

4 Miller LD, Stevens MB. Skeletal manifestations of polymyalgia rheumatica. $7 A M A$ 1978;240: 27-9.

5 Horslev-Peterson K, Helin P. Coexistence of temporal arteritis and rheumatoid arthritis. I Rheumatol 1983;10:831-2.

(Accepted 31 fanuary 1986)

Division of Rheumatology, Northwick Park Hospital and Clinical Research Centre, Harrow, Middlesex HA1 3UJ

R G PALMER, DM, MRCP, senior registrar P J PROUSE, FRACP, senior registrar J M GUMPEL, FRCP, consultant physician

Correspondence to: Dr Palmer.

\section{Body mass index and mortality in the elderly}

It is common belief that an obese person should reduce weight in order to prolong life and keep healthy. According to population studies both underweight and especially overweight increase the risk of death. ${ }^{1}$ Nevertheless, the importance of overweight remains a subject of controversy. ${ }^{23}$ The consequences of obesity have been assumed to change with age. ${ }^{3}$ For the prevention and treatment of obesity we need more quantitative information about the relation between the degree of fatness and the degree of risk. ${ }^{4}$ In the case of the elderly, especially the very old, such information is lacking. ${ }^{2}$

\section{Study population, methods, and results}

In 1977 there were 674 people aged 85 or over living in Tampere, Finland. Of these, $526(78 \% ; 95$ men, 431 women $)$ were measured and weighed in conjunction with a general health survey. According to a questionnaire only five men and two women were still smoking.

The body mass index (weight $(\mathrm{kg}) /$ height $(\mathrm{m})^{2}$ ) was used as a measure of obesity. The mean body mass index in the 526 subjects was $23 \cdot 1$ (SD $4 \cdot 1$ ).

Survival in the study group was followed up until 31 December 1982. Mortality and relative survival rates were calculated as described. ${ }^{5}$ Expected survival rates of subgroups were calculated using life tables of the Finnish population aged 85 or over in 1976-80 analysed by sex and one year age groups. When survival of the group examined corresponded to the survival of the total Finnish population of the same sex and age the relative survival rate was taken as one. Values over one represent lower mortality, values less than one higher, and the more the value deviates from one the greater is the divergence from average.

The highest five year mortality $(87 \%)$ was observed in the group with a body mass index of under $20.0(n=103)$ and the lowest mortality $(53 \%)$ in those with a body mass index of $30^{\circ} 0$ or higher $(n=41)$. Mortality consistently decreased with increasing weight. The relative survival curves of the subgroups with a body mass index of $22 \cdot 0$ or more did not differ significantly from each other (figure).

\section{Comment}

In this comparison of survival the methods used corrected for the preponderance of women and the difference in ages between the sexes in the cohort. These methods were necessary as both body mass index and mortality are associated with age and sex.

Change in lifelong habits of nutrition and physical activity in the elderly is difficult to introduce and may cause considerable trouble, discomfort, and anxiety. We must therefore have sufficient grounds for suggesting that an old person should lose weight. Furthermore, our findings show that in the very old the risk of death does not increase with the body mass index. Hence in these people overweight is no longer a risk factor or indicator for risk of death-and moderate overweight may, in fact, be a sign of good health. 


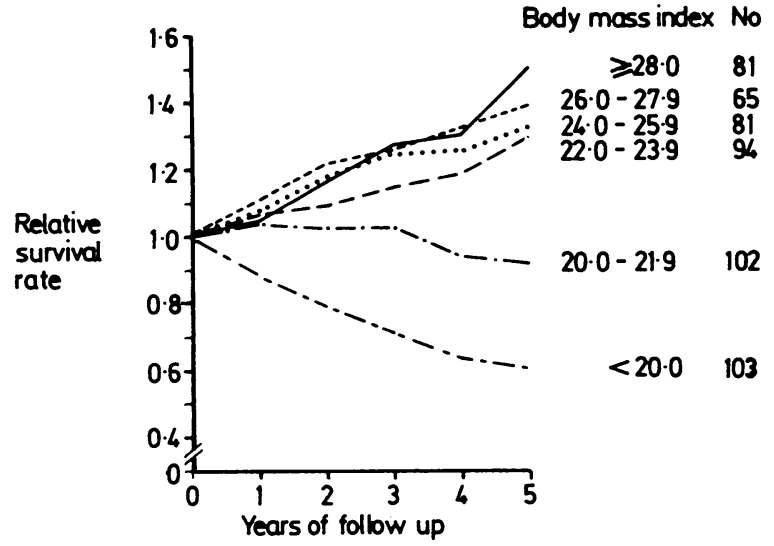

Five year relative survival curves according to body mass index in subjects aged 85 and over.

There seems to be no sense in worrying very old people to reduce weight to increase their life span.

A low body mass index is more relevant than a high body mass index in predicting the risk of death in the very old.

This study was supported by the Yrjö Jahnsson Foundation of Finland.

1 Waaler HT. Height, weight and mortality. The Norwegian experience. Acta Med Scand 1983;suppl 679:1-56.

2 Andres R. Influence of obesity on longevity in the aged. In: Danon D, Shock NW, Marois N, eds. Ageing: a challenge to science and sociery. Vol 1. Oxford: Oxford University Press, 1981:196-203.

Ageing: a challenge to scence and sockety. Vol 1 . Oxford: Oxford University Press, 1981:196-203.
3 Jarret RJ, Shipley MJ, Rose G. Weight and mortality in the Whitehall study. Br Med 7 1982;285:535-7.

4 Department of Health and Social Security, Medical Research Council. Research on obesity. London: HMSO, 1976.

5 Hakulinen T. Cancer survival corrected for heterogeneity in patient withdrawal. Biometrics 1982;38:933-42.

(Accepted 14 January 1986)

Department of Public Health, University of Tampere, Box 607, SF-33101 Tampere 10, Finland

K MATTILA, MD, acting professor of gerontology

Department of Geriatric Medicine, City Hospital of Tampere, SF-33500 Tampere, Finland

M HAAVISTO, MD, senior physician

S RAJALA, MD, senior physician

Correspondence to: Professor Mattila.

\section{Wenckebach's phenomenon induced by cough linctus}

We report a case of cardiac toxicity resulting from abuse of opiate squill linctus (Gee's linctus).

\section{Case report}

A 42 year old woman presented with syncope. She had a history of intermittent discomfort of the upper arms, usually precipitated by lifting something or stretching. During the previous three years she had noticed palpitations, which had become worse in recent months; they occurred at night, when she felt "missed beats." Her recent associated insomnia and tendency to constipation had been attributed to increasing stress in the home and in her second marriage. When seen at home by her general practitioner she appeared pale and unwell with an irregular pulse of $\mathbf{4 0}$ beats/minute. On her arrival at hospital her general state had improved. She was an anxious, tremulous, thin woman with an irregular radial pulse, due to dropped beats, of 60 beats/minute and a blood pressure of $130 / 85 \mathrm{~mm} \mathrm{Hg}$. The groups of muscles in the proximal arm and shoulder girdle showed only a slight reduction in power associated with active painful movements and appreciable muscle tenderness; there was no fatiguability. An electrocardiogram (figure) showed second degree atrioventricular block with Wenckebach's phenomenon and widespread changes in repolarisation. Serum viscosity and potassium and calcium concentrations were normal.

After 24 hours she became tearful and agitated and was considering discharging herself. It then transpired that for many years she had been taking opiate squill linctus regularly. It had initially been prescribed for a coryzal illness, but she had bought further supplies over the counter. Recently she had been taking over a bottle a day because of stress in the family. Oral diazepam and sublingual buprenorphine were given, resulting in relief within minutes. Over five days the electrocardiogram became normal and her muscular symptoms and signs resolved. The results of all further investigations, including cardiac and muscle enzyme activities, were normal. After explanation and psychiatric assessment she was discharged to outpatient follow up. At review after one month she denied further intake of the linctus and 24 hour ambulatory electrocardiography showed no rhythm disturbances. She did, however, request more diazepam and buprenorphine.
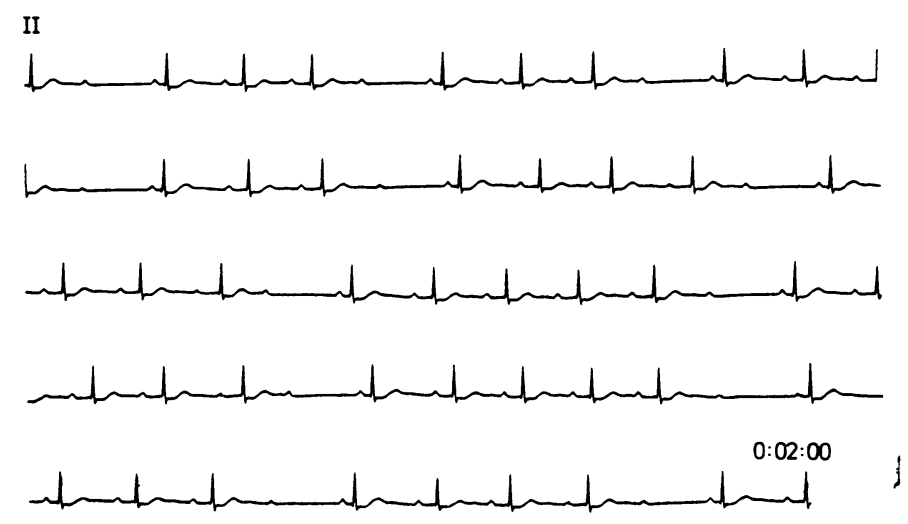

Electrocardiogram showing second degree atrioventricular block with Wenckebach's phenomenon and repolarisation changes.

\section{Comment}

There have been two reports of toxicity resulting from linctus codeine (Australian Pharmaceutical Formulary). ${ }^{12}$ Reversible cardiotoxicity, like that caused by digitalis, and electrocardiographic changes were present. Our case illustrates Mobitz type 1 second degree atrioventricular block after abuse of opiate squill linctus. The common factor is a cardiac glycoside, squill. Opiate squill linctus contains camphorated opium tincture, squill oxymel, tolu syrup, tragacanth, and xanthan; $5 \mathrm{ml}$ contains $800 \mu \mathrm{g}$ of anhydrous morphine. Squill is obtained from a Mediterranean bulbous plant, Urginea maritima, and most work on it was reported before $1924 .^{3}$ The major components are scillerans $\mathrm{A}$ and $\mathrm{B}$, chemically classified as cardiac glycosides. The pharmacodynamic properties of squill are considerable, being similar to those of digitalis, but it has a more potent vagal and diuretic action. Indeed, its diuretic properties were well recognised in Greek culture, though there is no reference to its therapeutic range. ${ }^{4}$ More recently it was a constituent of Guy's pill, in which it was combined with one grain each of prepared digitalis and mercury blue pill. ${ }^{5}$

The cardiac effects can be attributed to squill. The cause of the neuromuscular changes, however, is less certain. Nevertheless, in the case reported by Killpatrick muscle weakness did not recur when pholcodine linctus, a formulation not containing squill, was substituted. ${ }^{2}$ The combination of opiates as a cough suppressant together with squill, which is thought to act as an expectorant, is illogical. Kennedy suggested that squill be removed from the Australian preparation to avert further cases of toxicity. ${ }^{1}$ As there is little evidence that justifies their use perhaps cough mixtures containing squill should simply be withdrawn.

We thank Dr H James, consultant psychiatrist; Dr D Thrush, consultant neurologist; Mrs C Beer; and Mrs E A Howard for their help.

1 Kennedy M. Cardiac glycoside toxicity. An unusual manifestation of drug addiction. Med $\mathcal{J}$ Aust $1981 ; 2: 686$.

2 Killpatrick C. Myopathy with myasthenic features possibly induced by codeine linctus. Med $\mathcal{J}$ Aust $1982 ; 2: 410$.

3 Gemmil CL. The pharmacology of squill. Bull NY Acad Med 1974;50:747.

4 Stannard $\mathrm{J}$. Squill in ancient and medieval materia medica with special references to its employment for dropsy. Bull NY Acad Med 1974;50:750.

5 Hollman A. Plants and cardiac glycosides. Br Heart f 1985;54:258-61

(Accepted 12 February 1986)

Department of Cardiology, Greenbank Hospital, Plymouth General Hospital, Plymouth PLA 8NN

W SMITH, MB, MRCP, senior house officer

B A GOULD, MD, MRCP, senior registrar

A J MARSHALL, MD, MRCP, consultant cardiologist

Correspondence to: Dr Marshall. 